\title{
Review
}

\section{Challenges in 3D Live Cell Imaging}

\author{
Herbert Schneckenburger *(1) and Verena Richter \\ Institute of Applied Research, Aalen University, Beethovenstr. 1, 73430 Aalen, Germany; \\ Verena.Richter@hs-aalen.de \\ * Correspondence: Herbert.Schneckenburger@hs-aalen.de
}

Citation: Schneckenburger, $\mathrm{H}_{\text {. }}$

Richter, V. Challenges in 3D Live Cell

Imaging. Photonics 2021, 8, 275.

https://doi.org/10.3390/photonics8070275

Received: 14 June 2021

Accepted: 9 July 2021

Published: 13 July 2021

Publisher's Note: MDPI stays neutral with regard to jurisdictional claims in published maps and institutional affiliations.

Copyright: (c) 2021 by the authors. Licensee MDPI, Basel, Switzerland. This article is an open access article distributed under the terms and conditions of the Creative Commons Attribution (CC BY) license (https:/ / creativecommons.org/licenses/by/ $4.0 /)$.

\begin{abstract}
A short overview on 3D live cell imaging is given. Relevant samples are described and various problems and challenges-including 3D imaging by optical sectioning, light scattering and phototoxicity - are addressed. Furthermore, enhanced methods of wide-field or laser scanning microscopy together with some relevant examples and applications are summarized. In the future one may profit from a continuous increase in microscopic resolution, but also from molecular sensing techniques in the nanometer range using e.g., non-radiative energy transfer (FRET).
\end{abstract}

Keywords: 3D cell cultures; light scattering; phototoxicity; wide-field microscopy; laser scanning microscopy; structured illumination; light sheet microscopy; FRET

\section{Introduction}

Experimental and pre-clinical life cell approaches traditionally use two-dimensional (2D) cell cultures, which are easy to establish, but frequently provide results of limited significance, since cells are lacking a physiological microenvironment. In contrast, threedimensional (3D) cell cultures, e.g., multicellular tumor spheroids (MCTS), maintain tissuelike properties and therefore provide a more realistic background for experimental studies, e.g., screening of pharmaceutical agents [1,2]. However, imaging of 3-dimensional specimens is challenging, since the sample thickness commonly exceeds the depth of focus of a conventional detection system, and light scattering considerably impairs the image quality. Therefore, methods based on optical sectioning, e.g., confocal laser scanning microscopy (CLSM) [3,4], Optical Sectioning Structured Illumination Microscopy (OS-SIM) [5], or light sheet fluorescence microscopy (LSFM) [6,7] are applied preferentially. Here, images are recorded plane by plane, and resulting 3D plots are calculated offline. A problem for CLSM related methods as well as for OS-SIM is that for imaging each plane the whole sample has to be illuminated, so that upon recording of the whole specimen phototoxic damages are likely to occur [8]. Furthermore, photobleaching may increase in the course of an experiment and falsify the experimental results. Altogether, 3D imaging creates a large number of data ("big data"), which have to be handled appropriately.

\section{3D Samples}

Two-dimensional cell cultures have a well-established protocol in biomedical research and provide a simple, fast, and cost-effective tool for e.g., drug discovery assays. However, mammalian cells commonly grow within a complex three-dimensional microenvironment with a different gene expression and protein synthesis pattern [9]. Therefore, various 3D models have been established to better mimic the natural cell environment.

Cells embedded in hydrogels, e.g., agarose, which are readily accessed by optical sectioning methods like CLSM or OS-SIM may provide more realistic studies of cell morphology, e.g., to examine the influence of mechanical signals on cell behavior [10]. Multicellular (tumor) spheroids have gained significance in preclinical studies, as they appear to be more appropriate for studies of cell physiology, cell metabolism, or tissue diagnostics. 3D cultivation techniques commonly prevent cell attachment to surfaces, using hanging drop 
methods, liquid overlay methods or agitation-based approaches [11]. Cell cultivation in a solid matrix, e.g., agarose gel, may permit 3D cell growth under realistic conditions [12,13]. Cell spheroids are generally characterized by an external proliferating region and an internal quiescent zone (caused by the gradient of nutrient and oxygen diffusion), which may surround a necrotic core in larger spheroids [14].

Organoids are a type of 3D cell culture containing organ-specific cells that have been grown from a range of organs, including kidney, breast and liver (for a review see e.g., $[15,16])$. However, current 3D systems often lack a vasculature, which might support tissues with oxygen and nutrients, remove waste and build up an immune system. Nevertheless, organoid development is a rapidly growing field, and complex 3D systems including fully vascularized brain organoids [17] or organs-on-a-chip [18] have been reported in recent studies.

Traditionally, biopsies from a histological laboratory are routinely fixed and either embedded in paraffin, or frozen as thin sections, stained and mounted on glass slides. These procedures, however, introduce artifacts and severely limit the information, as only a small fraction of a specimen is used for microscopy. Novel approaches of nondestructive slide-free pathology are investigated, which allow deep volumetric microscopy of whole biopsy specimens [19]. Imaging of whole organisms is an important tool in developmental biology as well as drug screening [20]. Microscopy of small organisms requires either high transparency or the application of optical clearing techniques (see below), if viability is not a main criterion.

Measurements of 3D (cell) cultures often need specific sample holders, e.g., glass or plastic tubes or even micro-capillaries, which may be rotated for multi-view applications (see e.g., [21]).

\section{Phenomena and Challenges}

\subsection{Light Scattering}

Interaction of light with any kind of samples is described in terms of absorption and scattering. In particular, light scattering experiments with angular or spectral resolution have been used for more than 30 years for characterization of various types of cells $[22,23]$ or for measurement of morphological changes in cells undergoing necrosis or apoptosis [24,25]. However, scattering reduces the quality of images due to light attenuation, blurring and a loss of contrast. Obviously, these problems are more severe for three-dimensional than for two-dimensional samples, since scattering does not only occur in a certain plane of detection, but also creates background signals from the whole illuminated volume. This is well documented by Figure 1 showing 3D spheroids of Chinese hamster ovary $(\mathrm{CHO})$ cells of about $250 \mu \mathrm{m}$ diameter expressing a membrane-associated Green Fluorescent Protein (GFP). Conventional fluorescence microscopy (Figure 1a) shows a completely blurred image, since information from the focal plane is superposed by outof-focus images, and since pronounced scattering further reduces the image quality. The impact of scattering appears lower, if individual planes of the sample are selected either by confocal laser scanning microscopy (CLSM) or by light sheet fluorescence microscopy (LSFM). Nevertheless, a loss of fluorescence intensity occurs in the central parts of the CLSM image (Figure 1b) and along the direction of light propagation in the LSFM image (Figure 1c). Obviously, light attenuation is less pronounced in the LSFM image, where due to the anisotropy of Mie scattering [26] light is scattered preferentially into forward direction. However, some stripes in the direction of light incidence are often unavoidable. Scattering is becoming lower at higher wavelengths, which are used preferentially in multiphoton microscopy $[27,28]$. 

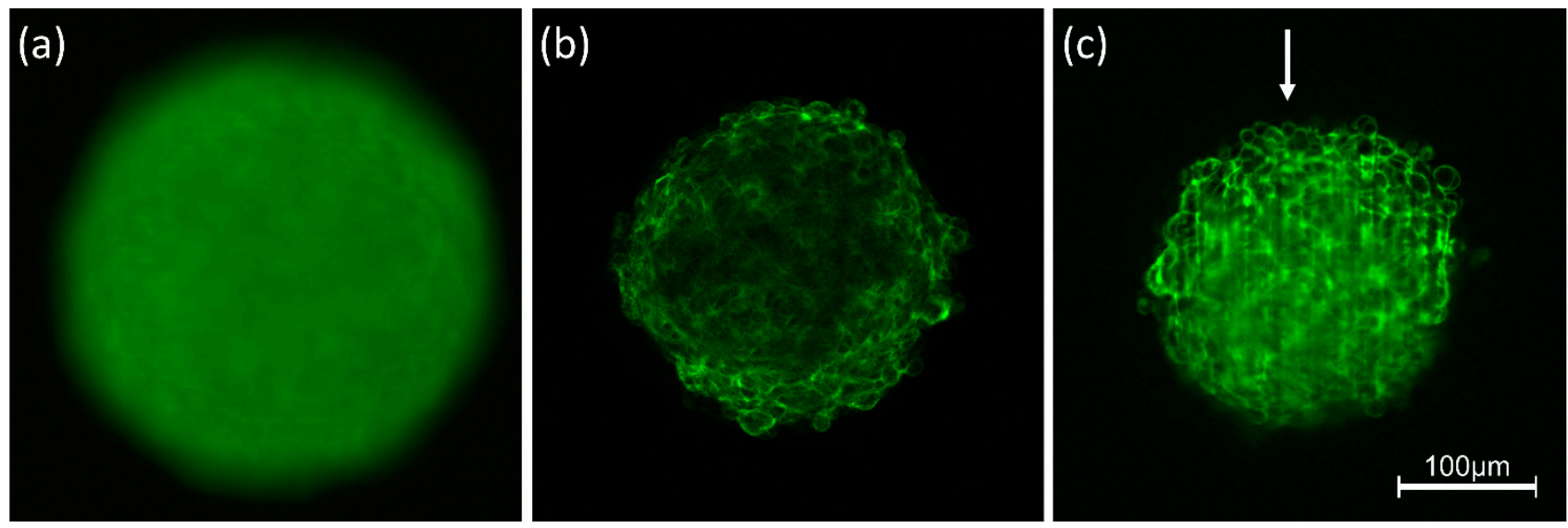

Figure 1. Spheroids of CHO-pAcGFP1-Mem cells recorded by conventional fluorescence microscopy (a), CLSM (b) and LSFM (c). Single planes are selected in $(\mathbf{b}, \mathbf{c})$ at a depth of $60 \mu \mathrm{m}$ within the spheroid; arrow indicates direction of light incidence in LSFM (excitation wavelength: $488 \mathrm{~nm}$; fluorescence detected at $\lambda \geq 505 \mathrm{~nm}$ ).

For reduction of light scattering optical clearing techniques matching the refractive indices of sample and surrounding medium have gained considerable importance. Therefore, these techniques are used increasingly for deep view imaging of skin, brain and other organs [29-31]. Currently available optical clearing techniques are not compatible with live cell imaging. However, efforts are being made to find biocompatible solutions, especially for ex-vivo applications [32]. While penetration depths are limited to $100-200 \mu \mathrm{m}$ in non-cleared samples, they can be even larger than $0.5 \mathrm{~mm}$ in cleared samples, permitting e.g., to image entire neuronal networks in mouse brains.

\subsection{Phototoxicity, Photobleaching}

As reported above, $3 \mathrm{D}$ images are often based on optical sectioning, and information is summed up from z-stacks of individual exposures. Only for LSFM, each sectional image results from one illuminated plane, whereas for other wide-field and laser scanning techniques, the whole specimen has to be illuminated for each image section. This implies that light exposure for obtaining a 3D image is summing up and often exceeds the limit of nonphototoxic light doses. Tolerable light doses were determined in a previous manuscript [8] and ranged between $25 \mathrm{~J} / \mathrm{cm}^{2}(375 \mathrm{~nm})$ and $200 \mathrm{~J} / \mathrm{cm}^{2}(633 \mathrm{~nm})$ for cultures of native cells, thus increasing with illumination wavelength and corresponding to $4 \mathrm{~min}$. up to about $30 \mathrm{~min}$. of solar irradiance (around $100 \mathrm{~mW} / \mathrm{cm}^{2}$ ). If cells were stained with a fluorescent dye or transfected with a fluorescent protein, typical non-phototoxic light doses were only around $10 \mathrm{~J} / \mathrm{cm}^{2}$, corresponding to $100 \mathrm{~s}$ of solar irradiance. In Figure 2, a maximum number of images is indicated for the case that cells are illuminated with $100 \mathrm{~mW} / \mathrm{cm}^{2}$ (corresponding to $1 \mathrm{nW} / \mu^{2}$ ) for $1 \mathrm{~s}$ (wide-field images) or $5 \mathrm{~s}$ (laser scanning image). While only about 20 layers of a 3D cell spheroid can thus be irradiated once by CLSM, each layer can be illuminated about 100 times by LSFM. This favors light sheet microscopy for long-term experiments in cell or developmental biology.

In previous studies [33] we found that non-phototoxic light doses did not depend on whether the light was applied continuously or in short pulses. This implies that for multiphoton imaging (see Section 4.1) the integral light dose and the wavelength of illumination appear to be the main limiting factors. Therefore, due to the longer wavelengths phototoxicity is generally lower for multiphoton than for single photon imaging.

Increasing sensitivities of novel detection systems (e.g., ultra-sensitive cameras) will increase the number of images measured at non-phototoxic light doses and will permit recording of fast dynamic processes, e.g., rapid cell migration, membrane or microtubule dynamics, mitochondrial motion as well as endo- or exocytosis. 


\begin{tabular}{|c|c|c|c|c|}
\hline Method & Experiment & $\begin{array}{c}\text { Max.light dose } \\
{\left[\mathrm{J} / \mathrm{cm}^{2}\right]}\end{array}$ & $\begin{array}{c}\text { Irradiance } \\
{\left[\mathrm{mW} / \mathrm{cm}^{2}\right]}\end{array}$ & $\begin{array}{c}\text { Max. no. of } \\
\text { images }\end{array}$ \\
\hline Wide-field microscopy & Autofluorescence & 25 & 100 & 250 \\
\hline Wide-field microscopy & Fluorescence marker & 10 & 100 & 100 \\
\hline CLSM & Fluorescence marker & 10 & 100 & 20 \\
\hline LSFM (N layers) & Fluorescence marker & 10 & 100 & $\mathrm{~N} \times 100$ \\
\hline
\end{tabular}

Figure 2. Maximum non-phototoxic light doses and maximum number of images for various methods of $3 \mathrm{D}$ live cell imaging. For autofluorescence experiments an excitation wavelength of $375 \mathrm{~nm}$ is assumed. An exposure time of $5 \mathrm{~s}$ is assumed for LSFM, and a time of $1 \mathrm{~s}$ for all other (wide-field) techniques (data partly reproduced from [8]).

A further phenomenon upon pronounced light exposure is photobleaching or fluorescence bleaching. This effect may be concomitant with modification or destruction of a specific fluorophore [34] and makes quantitative evaluation of fluorescence signals difficult. In some cases, intersystem crossing to a (non-fluorescent) excited triplet state occurs, and after deactivation of this state the corresponding molecules may fluoresce again ("fluorescence recovery"). This effect often causes characteristic "blinking" and is used in single molecule spectroscopy (for a review see [35]). For more than 40 years "fluorescence recovery after photobleaching" (FRAP) has been applied to measure cell, membrane and, in particular, protein dynamics (for reviews see [36,37]). In this case, part of a fluorescent specimen is photobleached, and re-diffusion of molecules from outside this part is measured. However, this method should be applied with care since high light exposure may damage living specimens.

\section{3. "Big Data"}

3D live cell imaging, especially light sheet microscopy of larger specimens, generates large datasets that need to be stored and processed. Multimodal configurations, e.g., timelapse or multispectral devices, or high-throughput/high-content setups add even more data leading to multidimensional datasets in the gigabyte or even terabyte range $[38,39]$. High-end computer hardware and central networks for efficient storage and retrieval of data as well as for fast processing of huge datasets and appropriate data management are needed. Open source software applications, e.g., OME Remote Objects (OMERO), enable access to and use of a wide range of biological data and provide open, flexible solutions for data management [40]. Recently, automated image processing and machine learning have become valuable tools to extract meaningful information from large datasets. As cells can be regarded as highly controlled objects, microscopy is well suited to pattern recognition tools based on neural networks and deep learning [41]. Several commercial (Imaris, Amira, Arivis) as well as non-commercial (BigDataViewer plugin for FIJI/ImageJ [42], ilastik [43]) software applications for high-performance $3 \mathrm{D}$ visualization and analysis are available.

\section{3D Microscopy}

For many imaging applications optical microscopy and, in particular, fluorescence microscopy plays a predominant role, and, therefore, relevant techniques are summarized in this section.

\subsection{Confocal Laser Scanning Microscopy}

In Confocal Laser Scanning Microscopy (CLSM) samples are scanned point by point, resulting in a two-dimensional image within typically a few seconds. A spatial pinhole in a conjugate image plane is used to block out-of-focus light thus acquiring optical sections with high contrast, as depicted in Figure 3. Information (e.g., fluorescence) from individual 
planes is then used for 3D image reconstruction by appropriate software. However, the whole procedure needs comparatively long scanning times and high light exposure, which may damage living specimens. One possibility to reduce light exposure is simultaneous illumination of several parts of a sample by Spinning Disk Confocal Microscopy [44].
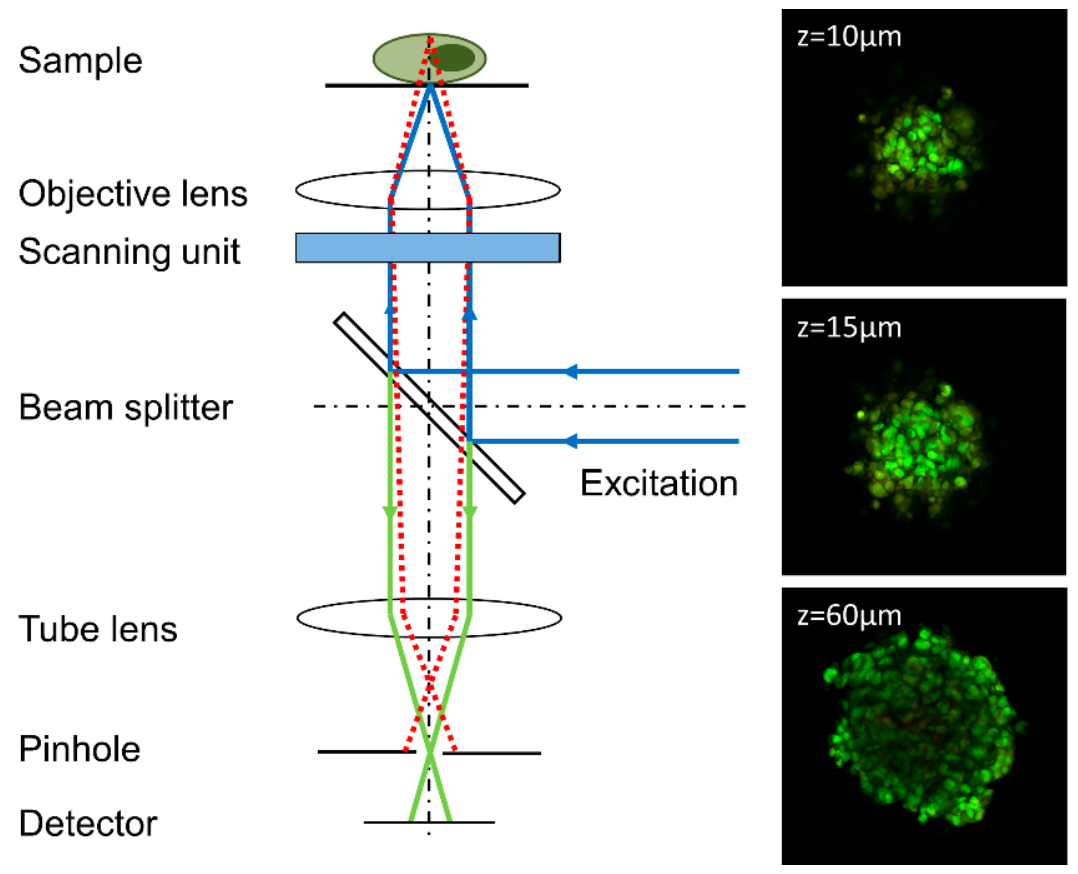

Figure 3. Principle of a confocal laser scanning microscope (CLSM); only a confocal beam passes the pinhole, whereas non-confocal beams are blocked. Moving of the sample in vertical direction allows imaging of different planes. Example: Focal planes of a spheroid of U373-MG glioblastoma cells incubated with acridine orange $(5 \mu \mathrm{M}, 40 \mathrm{~min}$.) at different distances from top of the sphere (excitation wavelength: $488 \mathrm{~nm}$, fluorescence detection: $\geq 505 \mu \mathrm{m}$, image size: $460 \mu \mathrm{m} \times 460 \mu \mathrm{m}$ ). Reproduced in parts from [33].

In a classical laser scanning setup resolution is only slightly improved compared to wide-field microscopes (see below). If, however, the pinhole selects only a small part of the diffraction pattern ("Airy disk") of individual points, the resolution may be improved up to almost a factor 2, while the detection sensitivity is reduced considerably. To circumvent this problem, the single pinhole has recently been replaced by an array of several individual detectors (Airy Scan Microscopy [45]), or by an ultrasensitive camera chip, where each pixel behaves as an "infinitely small pinhole" (Image Scan Microscopy [46]). Alternatively, resolution as well as sensitivity can be improved significantly by scanning the pinhole with another laser (Re-Scan Confocal Microscopy [47]).

Multiphoton microscopy (MPM) achieves optical sectioning by focusing picosecond or femtosecond laser pulses onto a small spot in the sample, thus exciting fluorescence by two or more photons in the small focal volume during an extremely short time without the need of any pinhole $[27,48]$. The scanning process and vertical displacement of the specimen is the same as for CLSM. Although multiphoton microscopes have vastly improved over the last 10 years, MPM still has some limitations in terms of the temporal resolution and long-term applicability as well as instrumentational challenges, e.g., suitable objective lenses for NIR transmission [49,50].

\subsection{Widefield Microscopy}

In conventional wide-field microscopy, an image is generated from the focal plane of a sample with a lateral resolution $\Delta \mathrm{x} \geq \lambda / 2 \mathrm{~A}_{N}$, as defined by the Abbe criterion for the case of coherent illumination. Alternatively, the Rayleigh criterion $\Delta x=0.61 \lambda / \mathrm{A}_{N}$ defines the 
resolution of a luminescent spot or an object illuminated incoherently with the wavelength $\lambda$ and the numerical aperture $A_{N}$ of the microscope objective lens. In both cases values around $200 \mathrm{~nm}$ are achieved for numerical apertures $A_{N} \geq 1.30$ at $\lambda=500 \mathrm{~nm}$. Often the axial resolution is related to the depth of focus $\Delta z=n \lambda / A_{N}{ }^{2}$, resulting in $\Delta z \geq 400 \mathrm{~nm}$ for the refractive index $n=1.50$. This implies that the focal plane is very thin, and a lot of out-of-focus information blurs the image considerably. Therefore, similar to CLSM, optical sectioning is often necessary.

Optical Sectioning Structured Illumination Microscopy (OS-SIM) is a wide-field technique to separate in-focus information from signals generated in out-of-focus planes. To achieve this, an optical grid is imaged in the plane of the sample in 3 phase positions $\Phi_{1}=0, \Phi_{2}=2 \pi / 3$ and $\Phi_{3}=4 \pi / 3$ resulting in the intensities $\mathrm{I}_{1}, \mathrm{I}_{2}$ and $\mathrm{I}_{3}$. An algorithm $\mathrm{I}=\left[\left(\mathrm{I}_{1}-\mathrm{I}_{2}\right)^{2}+\left(\mathrm{I}_{1}-\mathrm{I}_{3}\right)^{2}+\left(\mathrm{I}_{2}-\mathrm{I}_{3}\right)^{2}\right]^{1 / 2}$ permits to calculate an image from the focal plane, while out-of-focus images add up to zero, as depicted in Figure 4. Upon variation of the sample's vertical position, several focal planes can thus be detected, and a 3D image may be calculated [5]. While Figure 4 shows the principle of this method, Figure 5 shows an application to $\mathrm{CHO}$ cells transfected with a membrane associated Green Fluorescence Protein (GFP).

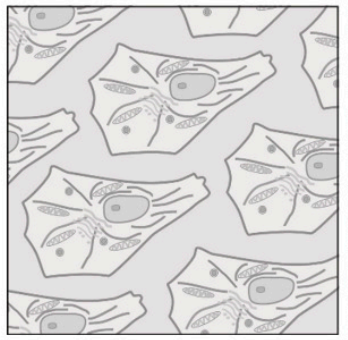

Original image

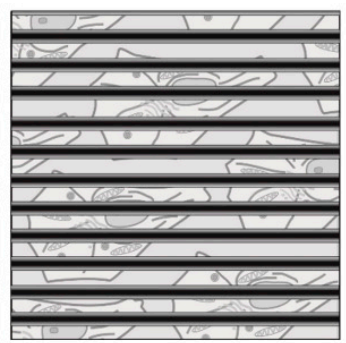

$\Phi_{1}=0 \rightarrow \mathrm{I}_{1}$

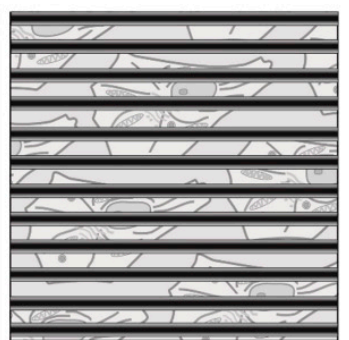

$\Phi_{2}=2 \pi / 3 \rightarrow \mathrm{I}_{2}$

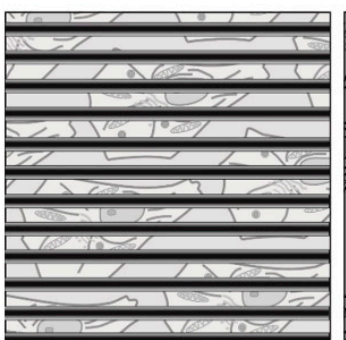

$\Phi_{3}=4 \pi / 3 \rightarrow I_{3}$

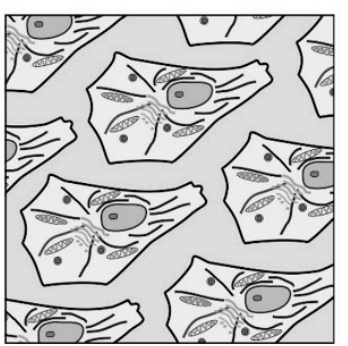

Image section

Figure 4. Principle of Optical-Sectioning Structured Illumination Microscopy (OS-SIM). Reproduced from [51] with modifications.
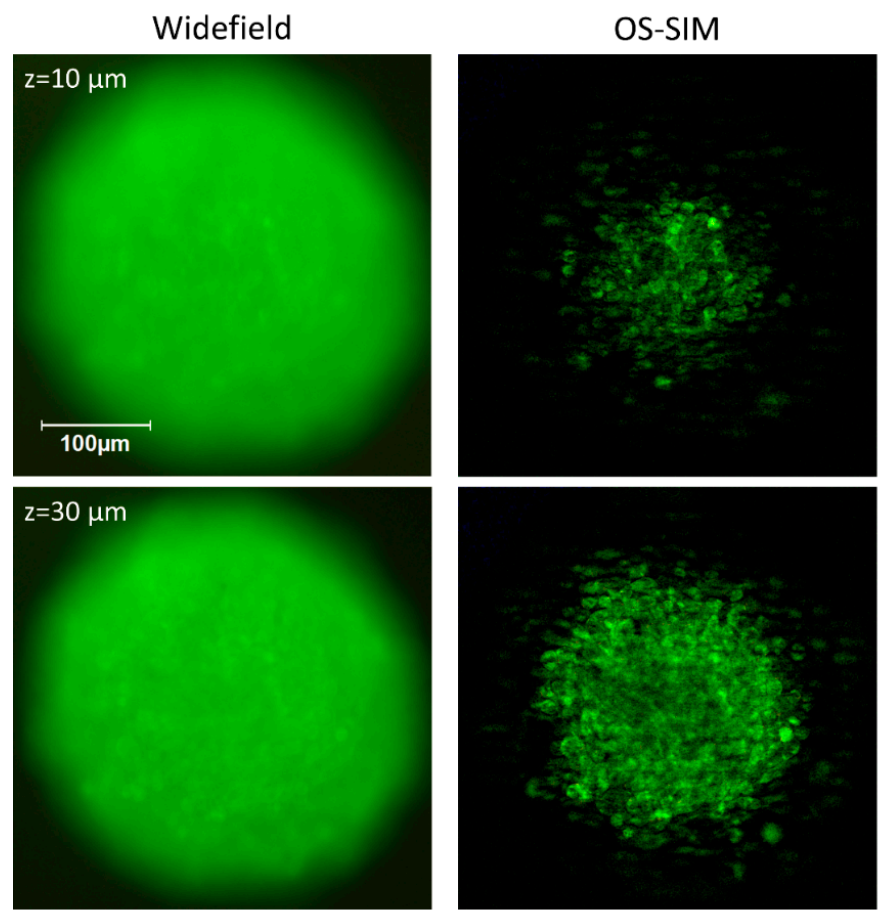

Figure 5. Spheroid of CHO-pAcGFP1-Mem cells. Conventional wide-field (left) and OS-SIM images (right) at different depths within the spheroid. While conventional wide-field microscopy includes a large amount of out-of-focus information, OS-SIM selects focal planes and resolves single cells. 
It should be added that Structured Illumination Microscopy can also be used for superresolution imaging with a 2-times enhancement of resolution in comparison with the Abbe criterion. In contrast to OS-SIM, "SR-SIM" [52,53]) is based on a coherent superposition of two or three laser beams modulated by an optical grid at different angles and phase positions. However, this technique is commonly limited to thin samples, as out-of-focus light degrades the quality of the grid pattern in the sample plane. In addition, acquisition of multiple (typically 9-15) raw images needed to reconstruct a single super-resolution frame takes relatively long time and thus reduces acquisition speed. These limitations can be overcome by illuminating the sample with a lattice pattern rather than grid lines, which gives higher contrast and allows a more robust image reconstruction $[54,55]$.

Light Sheet Fluorescence Microscopy (LSFM) is another wide-field method that uses optical sectioning with the sample being illuminated from the side (at $90^{\circ}$ with respect to the microscope axis) by either a cylindrical lens or scanning of a laser beam. For 3D imaging, the light sheet and the microscope objective lens used for detection can be shifted simultaneously in axial direction, so that the illuminated part of the sample is always in the focus of the objective lens. Both shifts may be different due to the refractive index of the immersion fluid, but this can be corrected either mechanically [56] or by software. Alternatively, the sample can be moved in axial direction through a static light sheet. Thus, z-stacks can be recorded with low fluorescence background and high contrast, as depicted in Figure 6 for spheroids of MCF-7 breast cancer cells incubated with the cytotoxic drug doxorubicin. A 3D image can be calculated offline from these images, as described elsewhere [57]. The main advantage of Light Sheet over OS-SIM is that only those planes are illuminated, which are recorded simultaneously, so that light exposure is considerably lower than for those methods, where recording of each image requires illumination of the whole specimen. Commercial light-sheet microscopes (e.g., Carl Zeiss, Olympus, Nikon) as well as open-source solutions or add-ons for existing microscopes are presently available [56,58].

(a)

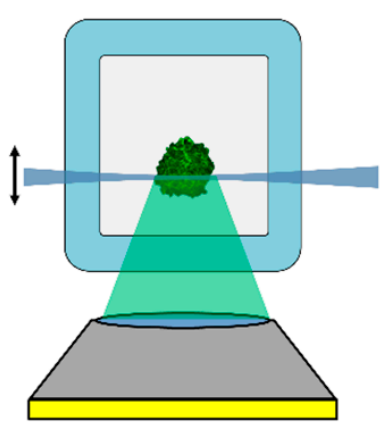

(b)

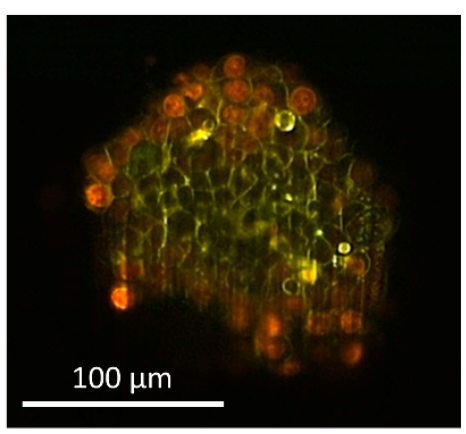

(c)

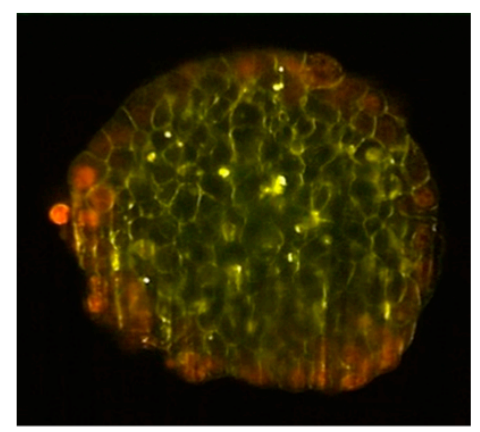

Figure 6. Principle of light sheet microscopy (a); image sections of MCF-7 spheroids incubated for 6 $\mathrm{h}$ with doxorubicin $(8 \mu \mathrm{M})$ at a depth of $20 \mu \mathrm{m}(\mathrm{b})$ or $60 \mu \mathrm{m}$ (c) within the spheroid. Red and greenyellow fluorescence permit distinction of doxorubicin and its degradation product. Reproduced from [57] with modifications.

With Axial Tomography specimens can be observed from various sides, and since the lateral resolution in microscopy is always better than the axial resolution, the vertical axis can be rotated into the horizontal position to profit from an enhanced isotropic resolution of about $200 \mathrm{~nm}$ for conventional wide-field microscopy or CLSM and about $100 \mathrm{~nm}$ for SR-SIM. However, rotation of samples needs specific sample holders and preparation techniques, e.g., cells embedded in a gel within a rotatable capillary, whose refractive index can be adapted to that of water or oil when using an immersion lens of high magnification [59]. A particular problem for 3D specimens is precise positioning of the samples upon rotation as well as appropriate reconstruction of 3D images. 
Recently, Light Field Microscopy became an interesting candidate for 3D imaging of fast biological processes, e.g., neural activity in whole animals [60,61]. It provides instant $3 \mathrm{D}$ excitation and single-shot volumetric recording that creates up to $2003 \mathrm{D}$ images per second, but requires a computationally demanding image reconstruction process and offers comparably low spatial resolution. Novel approaches to image reconstruction with deep-learning algorithms aim to overcome these limitations [62].

\subsection{Deconvolution}

In a diffraction-limited system, image formation can be described as a convolution of light emitted from each point in the object with the point spread function (PSF) of the microscope. Deconvolution, an image processing technique used to reverse this blurring process has been introduced almost 40 years ago, and with increasing memory capacity and calculation speed of personal computers 3D-deconvolution has become a well-established lab tool for deblurring of microscopy data from various 3D techniques [63-66]. Commercial deconvolution software packages, e.g., Huygens (Scientific Volume Imaging, Hilversum, The Netherlands) or Auto Quant (Media Cybernetics, Rockville, MD, USA) and public domain tools, e.g., Deconvolution LAB2 for FIJI [67], provide tools for 3D deconvolution, which are comparably easy to use even for non-specialists in computational image processing. Deconvolution algorithms are also used during image reconstruction for super resolution methods, e.g., SR-SIM [68,69] and Image Scanning Microscopy [46].

\section{Discussion}

3D imaging of living specimens is a very challenging topic requiring: (1) experience in the preparation and handling of 3D samples, (2) techniques of image sectioning and reconstruction, (3) minimization of light scattering, (4) light dosimetry, as well as (5) processing strategies for large datasets. Many experimental methods are based on light microscopy, but also macroscopic or endoscopic systems as well as multi-well screening techniques may be appropriate for certain specimens and applications. Since electron microscopy is difficult to realize for living cells due to fixation of samples and high irradiation doses [70], it is not further considered in this manuscript. However, "correlative microscopy", i.e., a combination of optical and electron microscopy presently gains considerable importance in optical nanoscopy. Often nanometer distances cannot be resolved within a microscope, but it is well known that fluorescence spectra as well as fluorescence lifetimes (for an overview see [71]) depend on the microenvironment of a relevant fluorophore, including $\mathrm{pH}$, viscosity, and polarity. For example, shortening of the fluorescence lifetime of GFP in close vicinity to cell membranes or to a cell-glass interface has been reported in the literature [72,73]. Molecular sensing techniques based on fluorescence spectra or lifetimes may be applicable also to 3D cell systems. This holds in particular for studies on Förster Resonance Energy Transfer (FRET), where after excitation of a so-called donor molecule excitation energy is transferred to an acceptor molecule by interaction of optical transition dipoles, if their distance is less than about $10 \mathrm{~nm}$ [74]. Applications to nanometer sensing in 3D systems include studies of subdomains of proteins [75], probing of molecular cell-biomaterial interactions [76] or monitoring of apoptosis by cleaving of a specific peptide linker [77]. In case of larger molecules adjacent in cellular micro-domains (e.g., membrane domains or intracellular organelles), or for studies of more than two interacting molecular populations, their co-localization can be quantified to analyze this interaction. Co-localization methods are based on two different, complementary methods: a pixel-based approach $[78,79]$ or an object-based approach [80,81], as well as a combination of the two approaches [82]. In the future one may expect further increase of resolution in microscopy at non-phototoxic light doses as well as novel highly specific applications of nanometer sensing in 3D cell systems.

\section{Conclusions}

We conclude that 3D live cell imaging is still a developing field for studying cell models with tissue-like properties, whole organs or intact organisms. Appropriate methods have 
been developed, which remain to be further elaborated. Novel preparation techniques, reduction or mathematical correction of light scattering, minimization of light exposure and phototoxicity, as well as processing of large data sets remain great challenges for the future.

Author Contributions: Conceptualization, H.S.; methodology, H.S., V.R.; software, V.R.; validation, H.S., V.R.; investigation, V.R.; resources, H.S.; data curation, V.R.; writing—original draft preparation, H.S. and V.R.; writing—review and editing, H.S.; visualization, V.R.; supervision, H.S.; funding acquisition, H.S. Both authors have read and agreed to the published version of the manuscript.

Funding: This review received no external funding.

Institutional Review Board Statement: Not applicable.

Informed Consent Statement: Not applicable.

Data Availability Statement: Not applicable.

Acknowledgments: CHO-pAcGFP1-Mem cells were kindly supplied by the Institute of Laser Technology in Medicine and Metrology (ILM) at the University of Ulm. The authors thank Michael Wagner for his cooperation and Claudia Hintze for skillful technical assistance.

Conflicts of Interest: The authors declare no conflict of interest.

\section{References}

1. Kunz-Schughart, L.A.; Freyer, J.P.; Hofstaedter, F.; Ebner, R. The Use of 3-D Cultures for High-Throughput Screening: The Multicellular Spheroid Model. J. Biomol. Screen. 2004, 9, 273-285. [CrossRef]

2. Wittig, R.; Richter, V.; Wittig-Blaich, S.; Weber, P.; Strauss, W.S.L.; Bruns, T.; Dick, T.-P.; Schneckenburger, H. Biosensor-expressing spheroid cultures for imaging of drug-induced effects in three dimensions. J. Biomol. Screen. 2013, 18, 736-743. [CrossRef]

3. Pawley, J. Handbook of Biological Confocal Microscopy, 3rd ed.; Springer: Boston, MA, USA, 1990. [CrossRef]

4. Webb, R.H. Confocal optical microscopy. Rep. Prog. Phys. 1996, 59, 427-471. [CrossRef]

5. Neil, M.A.; Juskaitis, R.; Wilson, T. Method of obtaining optical sectioning by using structured light in a conventional microscope. Opt. Lett. 1997, 22, 1905-1907. [CrossRef]

6. Pampaloni, F.; Chang, B.-J.; Stelzer, E.H.K. Light sheet-based fluorescence microscopy (LSFM) for the quantitative imaging of cells and tissues. Cell Tissue Res. 2015, 362, 265-277. [CrossRef] [PubMed]

7. Santi, P.A. Light sheet fluorescence microscopy: A review. J. Histochem. Cytochem. 2011, 59, 129-138. [CrossRef] [PubMed]

8. Schneckenburger, H.; Weber, P.; Wagner, M.; Schickinger, S.; Richter, V.; Bruns, T.; Strauss, W.S.L.; Wittig, R. Light exposure and cell viability in fluorescence microscopy. J. Microsc. 2012, 245, 311-318. [CrossRef]

9. Bardsley, K.; Deegan, A.J.; El Haj, A.; Yang, Y. Current State-of-the-Art 3D Tissue Models and Their Compatibility with Live Cell Imaging. Adv. Exp. Med. Biol. 2017, 1035, 3-18. [CrossRef]

10. Cambria, E.; Brunner, S.; Heusser, S.; Fisch, P.; Hitzl, W.; Ferguson, S.J.; Wuertz-Kozak, K. Cell-laden agarose-collagen composite hydrogels for mechanotransduction studies. Front. Bioeng. Biotechnol. 2020, 8, 346. [CrossRef] [PubMed]

11. Lazzari, G.; Couvreur, P.; Mura, S. Multicellular tumor spheroids: A relevant 3D model for the in vitro preclinical investigation of polymer nanomedicines. Polym. Chem. 2017, 8, 4947-4969. [CrossRef]

12. Johnson, M.D.; Bryan, G.T.; Reznikoff, C.A. Serial cultivation of normal rat bladder epithelial cells in vitro. J. Urol. 1985, 133, 1076-1081. [CrossRef]

13. Dusny, C.; Grünberger, A.; Probst, C.; Wiechert, W.; Kohlheyer, D.; Schmid, A. Technical bias of microcultivation environments on single cell physiology. Lab Chip 2015, 15, 1822-1834. [CrossRef] [PubMed]

14. Edmondson, R.; Broglie, J.J.; Adcock, A.F.; Yang, L. Three-dimensional cell culture systems and their applications in drug discovery and cell-based biosensors. Assay Drug Dev. Technol. 2014, 12, 207-218. [CrossRef]

15. Van Ineveld, R.L.; Ariese, H.C.R.; Wehrens, E.J.; Dekkers, J.F.; Rios, A.C. Single-Cell Resolution Three-Dimensional Imaging of Intact Organoids. J. Vis. Exp. 2020, 5. [CrossRef] [PubMed]

16. Torres, S.; Abdullah, Z.; Brol, M.J.; Hellerbrand, C.; Fernandez, M.; Fiorotto, R.; Klein, S.; Königshofer, P.; Liedtke, C.; Lotersztajn, S.; et al. Recent Advances in Practical Methods for Liver Cell Biology: A Short Overview. Int. J. Mol. Sci. 2020, 21, 2027. [CrossRef]

17. Mansour, A.A.; Gonçalves, J.T.; Bloyd, C.W.; Li, H.; Fernandes, S.; Quang, D.; Johnston, S.; Parylak, S.L.; Jin, X.; Gage, F.H. An in vivo model of functional and vascularized human brain organoids. Nat. Biotechnol. 2018, 36, 432-441. [CrossRef]

18. Schneider, O.; Zeifang, L.; Fuchs, S.; Sailer, C.; Loskill, P. User-Friendly and Parallelized Generation of Human Induced Pluripotent Stem Cell-Derived Microtissues in a Centrifugal Heart-on-a-Chip. Tissue Eng. Part A 2019, 25, 786-798. [CrossRef]

19. Glaser, A.K.; Reder, N.P.; Chen, Y.; McCarty, E.F.; Yin, C.; Wei, L.; Wang, Y.; True, L.D.; Liu, J.T.C. Light-sheet microscopy for slide-free non-destructive pathology of large clinical specimens. Nat. Biomed. Eng. 2017, 1, 0084. [CrossRef] [PubMed]

20. Martinez, N.J.; Titus, S.A.; Wagner, A.K.; Simeonov, A. High-throughput fluorescence imaging approaches for drug discovery using in vitro and in vivo three-dimensional models. Expert Opin. Drug Discov. 2015, 10, 1347-1361. [CrossRef] 
21. Bruns, T.; Schickinger, S.; Schneckenburger, H. Sample holder for axial rotation of specimens in 3D Microscopy. J. Microsc. 2015, 260, 30-36. [CrossRef]

22. Brunstin, A.; Mullaney, P.F. Differential Light-Scattering from Spherical Mammalian Cells. Biophys. J. 1974, 14, 439-453. [CrossRef]

23. Mourant, J.R.; Johnson, T.M.; Doddi, V.; Freyer, J.P. Angular dependent light scattering from multicellular spheroids. J. Biomed. Opt. 2002, 7, 93-99. [CrossRef] [PubMed]

24. Mulvey, C.S.; Sherwood, C.A.; Bigio, I.J. Wavelength-dependent backscattering measurements for quantitative real-time monitoring of apoptosis in living cells. J. Biomed. Opt. 2009, 14, 064013. [CrossRef]

25. Mulvey, C.S.; Zhang, K.; Bobby Liu, W.H.; Waxman, D.J.; Bigio, I.J. Wavelength-dependent backscattering measurements for quantitative monitoring of apoptosis, part 2: Early spectral changes during apoptosis are linked to apoptotic volume decrease. $J$. Biomed. Opt. 2011, 16, 117002. [CrossRef]

26. Bohren, C.F.; Huffman, D.R. Absorption and Scattering of Light by Small Particles; Wiley-Interscience Publications: New York, NY, USA, 1998. [CrossRef]

27. König, K. Multiphoton microscopy in life sciences. J. Microsc. 2000, 200 Pt 2, 83-104. [CrossRef]

28. Miller, D.R.; Jarrett, J.W.; Hassan, A.M.; Dunn, A.K. Deep Tissue Imaging with Multiphoton Fluorescence Microscopy. Curr. Opin. Biomed. Eng. 2017, 4, 32-39. [CrossRef]

29. Costa, E.C.; Silva, D.N.; Moreira, A.F.; Correia, I.J. Optical clearing methods: An overview of the techniques used for the imaging of 3D spheroids. Biotechnol. Bioeng. 2019, 116, 2742-2763. [CrossRef]

30. Sdobnov, A.Y.; Lademann, J.; Darvin, M.E.; Tuchin, V.V. Methods for Optical Skin Clearing in Molecular Optical Imaging in Dermatology. Biochemistry (Moscow) 2019, 84 (Suppl. S1), S144-S158. [CrossRef]

31. Susaki, E.A.; Tainaka, K.; Perrin, D.; Yukinaga, H.; Kuno, A.; Ueda, H.R. Advanced CUBIC protocols for whole-brain and whole-body clearing and imaging. Nat. Protoc. 2015, 10, 1709-1727. [CrossRef]

32. Costantini, I.; Cicchi, R.; Silvestri, L.; Vanzi, F.; Pavone, F.S. In-vivo and ex-vivo optical clearing methods for biological tissues: Review. Biomed. Opt. Express 2019, 10, 5251-5267. [CrossRef]

33. Schneckenburger, H.; Richter, V.; Wagner, M. Live-Cell Optical Microscopy with Limited Light Doses; SPIE Spotlight Series; SPIE: Bellingham, WA, USA, 2018; Volume 42, p. 38. [CrossRef]

34. Song, L.; Hennink, E.J.; Young, I.T.; Tanke, H.J. Photobleaching Kinetics of Fluorescein in Quantitative Fluorescence Microscopy. Biophys. J. 1995, 68, 2588-2600. [CrossRef]

35. Moerner, W.E.; Shechtman, Y.; Wang, Q. Single-molecule spectroscopy and imaging over the decades. Faraday Discuss. 2015, 184, 9-36. [CrossRef]

36. Ishikawa-Ankerhold, H.C.; Ankerhold, R.; Drummen, G.P. Advanced fluorescence microscopy techniques-FRAP, FLIP, FLAP, FRET and FLIM. Molecules 2012, 17, 4047-4132. [CrossRef]

37. Lippincott-Schwartz, J.; Snapp, E.L.; Phair, R.D. The Development and Enhancement of FRAP as a Key Tool for Investigating Protein Dynamics. Biophys. J. 2018, 115, 1146-1155. [CrossRef]

38. Amat, F.; Höckendorf, B.; Wan, Y.; Lemon, W.C.; McDole, K.; Keller, P.J. Efficient processing and analysis of large-scale light-sheet microscopy data. Nat. Prot. 2015, 10, 1679-1696. [CrossRef]

39. Reynaud, E.G.; Peychl, J.; Huisken, J.; Tomancak, P. Guide to light-sheet microscopy for adventurous biologists. Nat. Methods 2015, 12, 30-34. [CrossRef] [PubMed]

40. Allan, C.; Burel, J.M.; Moore, J.; Blackburn, C.; Linkert, M.; Loynton, S.; MacDonald, D.; Moore, W.J.; Neves, C.; Patterson, A.; et al OMERO: Flexible, model-driven data management for experimental biology. Nat. Methods 2012, 9, 245-253. [CrossRef] [PubMed]

41. Orth, A.; Schaak, D.; Schonbrun, E. Microscopy, Meet Big Data. Cell Syst. 2017, 4, 260-261. [CrossRef] [PubMed]

42. Pietzsch, T.; Saalfeld, S.; Preibisch, S.; Tomancak, P. BigDataViewer: Visualization and processing for large image data sets. Nat. Methods 2015, 12, 481-483. [CrossRef]

43. Berg, S.; Kutra, D.; Kroeger, T.; Straehle, C.N.; Kausler, B.X.; Haubold, C.; Schiegg, M.; Ales, J.; Beier, T.; Rudy, M.; et al. ilastik: Interactive machine learning for (bio)image analysis. Nat. Methods 2019, 16, 1226-1232. [CrossRef]

44. Nakano, A. Spinning-disk confocal microscopy-A cutting-edge tool for imaging of membrane traffic. Cell Struct. Funct. 2002, 27, 349-355. [CrossRef]

45. Huff, J. The Airyscan detector from ZEISS: Confocal imaging with improved signal-to-noise ratio and super-resolution. Nat. Methods 2015, 12, i-ii. [CrossRef]

46. Müller, C.B.; Enderlein, J. Image Scanning Microscopy. Phys. Rev. Lett. 2010, 104, 198101. [CrossRef]

47. De Luca, G.M.; Breedijk, R.M.; Brandt, R.A.; Zeelenberg, C.H.; de Jong, B.E.; Timmermans, W.; Azar, L.N.; Hoebe, R.A.; Stallinga, S.; Manders, E.M. Re-scan confocal microscopy: Scanning twice for better resolution. Biomed. Opt. Express 2013, 4, $2644-2656$. [CrossRef]

48. Wildanger, D.; Medda, R.; Kastrup, L.; Hell, S.W. A compact STED microscope providing 3D nanoscale resolution. J. Microsc. 2009, 236, 35-43. [CrossRef] [PubMed]

49. Benninger, R.K.; Piston, D.W. Two-photon excitation microscopy for the study of living cells and tissues. Curr. Protoc. Cell Biol. 2013, 59, 4-11. [CrossRef] [PubMed]

50. Lecoq, J.; Orlova, N.; Grewe, B.F. Wide. Fast. Deep: Recent Advances in Multiphoton Microscopy of In Vivo Neuronal Activity. J. Neurosci. 2019, 39, 9042-9052. [CrossRef] 
51. Schneckenburger, H.; Richter, V. Laser Scanning versus Wide-Field-Choosing the Appropriate Microscope in Life Sciences. Appl. Sci. 2021, 11, 733. [CrossRef]

52. Heintzmann, R.; Cremer, C. Laterally modulated excitation microscopy: Improvement of resolution by using a diffraction grating. In Optical Biopsies and Microscopic Techniques III, Proceedings of the SPIE 3568, Stockholm, Sweden, 8-12 September 1998; SPIE: Bellingham, WA, USA, 1999; pp. 185-196. [CrossRef]

53. Gustafsson, M.G.L.; Shao, L.; Carlton, P.M.; Wang, C.J.R.; Golubovskaya, I.N.; Cande, W.Z.; Agard, D.A.; Sedat, J.W. Threedimensional resolution doubling in wide-field fluorescence microscopy by structured illumination. Biophys. J. 2008, 94, 4957-4970. [CrossRef]

54. Betzig, E. Excitation strategies for optical lattice microscopy. Opt. Express 2005, 13, 3021-3036. [CrossRef]

55. Heintzmann, R. Saturated patterned excitation microscopy with two-dimensional excitation patterns. Micron 2003, 34, $283-291$. [CrossRef]

56. Bruns, T.; Bauer, M.; Bruns, S.; Meyer, H.; Kubin, D.; Schneckenburger, H. Miniaturized modules for light sheet microscopy with low chromatic aberration. J. Microsc. 2016, 264, 261-267. [CrossRef]

57. Bruns, T.; Schickinger, S.; Schneckenburger, H. Single plane illumination module and micro-capillary approach for a wide-field microscope. J. Vis. Exp. 2014, 90, e51993. [CrossRef] [PubMed]

58. Greger, K.; Swoger, J.; Stelzer, E.H.K. Basic building units and properties of a fluorescence single plane illumination microscope. Rev. Sci. Instrum. 2007, 78, 023705. [CrossRef] [PubMed]

59. Richter, V.; Bruns, S.; Bruns, T.; Weber, P.; Wagner, M.; Cremer, C.; Schneckenburger, H. Axial Tomography in Live Cell Laser Microscopy. J. Biomed. Opt. 2017, 22, 91505. [CrossRef] [PubMed]

60. Levoy, M.; Ng, R.; Adams, A.; Footer, M.; Horowitz, M. Light field microscopy. ACM Trans. Graph. 2006, 25, 924-934. [CrossRef]

61. Prevedel, R.; Yoon, Y.G.; Hoffmann, M.; Pak, N.; Wetzstein, G.; Kato, S.; Schrödel, T.; Raskar, R.; Zimmer, M.; Boyden, E.S.; et al. Simultaneous whole-animal 3d imaging of neuronal activity using light-field microscopy. Nat. Methods 2014, 11, 727-730. [CrossRef]

62. Wagner, N.; Beuttenmueller, F.; Norlin, N.; Gierten, J.; Boffi, J.C.; Wittbrodt, J.; Weigert, M.; Hufnagel, L.; Prevedel, R.; Kreshuk, A. Deep learning-enhanced light-field imaging with continuous validation. Nat. Methods 2021, 18, 557-563. [CrossRef]

63. Wallace, W.; Schaefer, L.H.; Swedlow, J.R. A workingperson's guide to deconvolution in light microscopy. Biotechniques 2001, 31, 1076-1078. [CrossRef]

64. Verdaasdonk, J.S.; Stephens, A.D.; Haase, J.; Bloom, K. Bending the rules: Widefield microscopy and the Abbe limit of resolution. J. Cell. Physiol. 2014, 229, 132-138. [CrossRef]

65. Becker, K.; Saghafi, S.; Pende, M.; Sabdyusheva-Litschauer, I.; Hahn, C.M.; Foroughipour, M.; Jährling, N.; Dodt, H.-U. Deconvolution of light sheet microscopy recordings. Sci. Rep. 2019, 9, 17625. [CrossRef]

66. Guo, M.; Li, Y.; Su, Y.; Lambert, T.; Nogare, D.D.; Moyle, M.W.; Duncan, L.H.; Ikegami, B.; Santella, A.; Rey-Suarez, I. Rapid image deconvolution and multiview fusion for optical microscopy. Nat. Biotechnol. 2020, 38, 1337-1346. [CrossRef] [PubMed]

67. Sage, D.; Donati, L.; Soulez, F.; Fortun, D.; Schmit, G.; Seitz, A.; Guiet, R.; Vonesch, C.; Unser, M. DeconvolutionLab2: An open-source software for deconvolution microscopy. Methods 2017, 115, 28-41. [CrossRef] [PubMed]

68. Gustafsson, M.G.L. Surpassing the lateral resolution limit by a factor of two using structured illumination microscopy. J. Microsc. 2000, 198 Pt 2, 82-87. [CrossRef]

69. Chakrova, N.; Rieger, B.; Stallinga, S. Deconvolution methods for structured illumination microscopy. J. Opt. Soc. Am. A 2016, 33, B12-B20. [CrossRef] [PubMed]

70. De Jonge, N.; Peckys, D.B. Live Cell Electron Microscopy Is Probably Impossible. ACS Nano 2016, 10, 9061-9063. [CrossRef] [PubMed]

71. Datta, R.; Heaster, T.M.; Sharick, J.T.; Gillette, A.A.; Skala, M.C. Fluorescence lifetime imaging microscopy: Fundamentals and advances in instrumentation, analysis, and applications. J. Biomed. Opt. 2020, 25, 1-43. [CrossRef]

72. Tregidgo, C.; Levitt, J.A.; Suhling, K. Effect of refractive index on the fluorescence lifetime of green fluorescent protein. J. Biomed. Opt. 2008, 13, 031218. [CrossRef] [PubMed]

73. Richter, V.; Lanzerstorfer, P.; Weghuber, J.; Schneckenburger, H. Probing small distances in live cell imaging. Photonics 2021, 8, 176. [CrossRef]

74. Förster, T. Zwischenmolekulare Energiewanderung und Fluoreszenz. Ann. Phys. 1948, 437, 55-75. [CrossRef]

75. Viallet, P.M.; Vo-Dinh, T. Studying 3D subdomains of proteins at the nanometer scale using fluorescence spectroscopy. Methods Mol. Biol. 2005, 300, 165-189. [CrossRef]

76. Huebsch, N.D.; Mooney, D.J. Fluorescent resonance energy transfer: A tool for probing molecular cell-biomaterial interactions in three dimensions. Biomaterials 2007, 28, 2424-2437. [CrossRef]

77. Weber, P.; Schickinger, S.; Wagner, M.; Angres, B.; Bruns, T.; Schneckenburger, H. Monitoring of apoptosis in 3D cell cultures by FRET and light sheet fluorescence microscopy. Int. J. Mol. Sci. 2015, 16, 5375-5385. [CrossRef]

78. Li, Q.; Lau, A.; Morris, T.J.; Guo, L.; Fordyce, C.B.; Stanley, E.F. A syntaxin 1, Galphao, and N-type calcium channel complex at a presynaptic nerve terminal: Analysis by quantitative immunocolocalization. J. Neurosci. 2004, 24, 4070-4081. [CrossRef]

79. Manders, E.; Stap, J.; Brakenhoff, G.; Van Driel, R.; Aten, J.A. Dynamics of three-dimensional replication patterns during the S-phase, analysed by double labelling of DNA and confocal microscopy. J. Cell Sci. 1992, 103, 857-862. [CrossRef] 
80. Obara, B.; Jabeen, A.; Fernandez, N.; Laissue, P.P. A novel method for quantified, superresolved, three-dimensional colocalisation of isotropic, fluorescent particles. Histochem. Cell Biol. 2013, 139, 391-402. [CrossRef] [PubMed]

81. Gilles, J.F.; Dos Santos, M.; Boudier, T.; Bolte, S.; Heck, N. DiAna, An ImageJ tool for object-based 3D co-localization and distance analysis. Methods 2017, 155, 55-64. [CrossRef] [PubMed]

82. Jaskolski, F.; Mulle, C.; Manzoni, O.J. An automated method to quantify and visualize colocalized fluorescent signals. J. Neurosci. Methods 2005, 146, 42-49. [CrossRef] [PubMed] 